\title{
Coastal Ocean Modeling: Processes and Real-Time Systems
}

\author{
D. B. Haidvogel \\ Rutgers University - New Brunswick, New Jersey USA \\ J. Blanton \\ Skidaway Institute of Oceanography - Savannah, Georgia USA \\ J. C. Kindle \\ Naval Research Laboratory • Stennis Space Center, Mississippi USA \\ D. R. Lynch \\ Dartmouth College - Dartmouth, New Hampshire USA
}

\section{Introduction}

The coastal oceans are among the most challenging marine environments in the world. They are subject to the combined geometrical constraints of irregular coastlines and highly variable (steep and tall) bathymetry, and are forced both internally, laterally and surfacially by a complex array of tidal, wind and buoyancy forces on a broad range of space/time scales. The resulting coastal circulation patterns include both persistent and time-variable fronts, intense currents with strong spatial (offshore and/or vertical) dependence, coastal trapped waves, internally generated mesoscale variability, large horizontal water mass contrasts, strong vertical stratification, and regions of intense turbulent mixing in both surface and bottom boundary layers. An extended review of coastal physical processes, which complements the discussion below, is provided by Brink and Robinson (1998).

Numerical modeling of these areas of the world's ocean clearly requires very flexible, highly optimized models of significant dynamical complexity. In the past, limited computer resources led to the development of physically and/or geometrically simplified models. In recent years, however, models developed for lake and shelf-sea dynamics have become increasingly complex, and are now typically based on the fully nonlinear stratified "primitive equations." Haidvogel and Beckmann (1998) summarize an international inventory of coastal ocean circulation models and describe their general attributes.

This review has three objectives. First, we provide a brief description of the physical environment and processes which dominate regional circulation patterns on the U.S. continental shelves. Second, we describe three coastal circulation models in primary use in U.S. coastal waters, which taken together represent the present state-of-the-art in coastal circulation modeling in the U.S. Lastly, we discuss several ongoing real-time and near-real-time applications of these numerical circulation models.

\section{Physical Processes}

The physical settings of the coastal systems surrounding the U.S. can be partially distinguished by the various processes that tend to either mix or to stratify the water column. For buoyancy inputs that increase vertical stratification, the relative ease with which this stratification is destroyed is enhanced in shallow water where kinetic energy density is large. This kinetic energy can be provided by, for example, tides, wind-generated waves and currents, and internal dynamical instabilities.

It is the relative magnitude of mixing agents (tides, winds, convection due to surface cooling and evaporation) relative to those of stratifying agents (freshwater discharge, surface heating) which often enables one to physically contrast one coastal setting with another. The importance of one agent over another is influenced by the physical setting of a particular environment: wide versus narrow, or shallow versus deep, continental shelves; the presence or absence of strong boundary currents; buoyancy sources such as large rivers; and atmospheric fluxes of momentum and/or moisture.

Circulation regimes brought about by wind stress, bottom friction and buoyancy forces are further modi- 
fied by site-specific features such as capes and canyons. These features change the along-margin flow and induce significant cross-margin currents. Localized upwellings at these sites enhance biological production. Capes, such as Cape Hatteras (Atlantic) and Point Conception (Pacific), may be the sites where large quantities of material are produced either to be transported to the open ocean or to settle and be recycled back to coastal margins.

\section{Vertical Mixing Processes}

Fluctuations in kinetic energy occur at time scales that are different in coastal areas than in open ocean areas. Weather systems input energy at frequencies of 0.1 to 0.3 cycles/day ( $3-10$ day periods), and a major portion of the kinetic energy spectrum in coastal areas is found at these frequencies. Open ocean variation of kinetic energy occurs at much lower frequencies (i.e. 0.01 to 0.02 cycle/day). The kinetic energy of currents due to astronomical tides is also higher in coastal than in open ocean regimes. Thus, coastal environments contain more high-frequency variability than do open ocean environments at similar depths.

Wind stress at the air-sea interface imparts kinetic energy to the water in the form of ocean currents and surface gravity waves. Momentum is transferred downward and toward the bottom where the energy is finally dissipated. In shallow water, the downward transfer of momentum reaches the bottom before much kinetic energy is lost, thus providing an efficient source of energy which can mix the water. The shallower the water, the more efficiently mixing occurs throughout the depth range. The intensity of surface wind stress, and the rate at which its momentum is transferred downward is particularly important in determining the bed stress during a major wind event. In addition to these effects, turbulence at the bottom associated with the surface wind wave field can significantly enhance bed stress and may cause major sediment movement.

Tidal forces provide kinetic energy for vertical and horizontal mixing. Tidal kinetic energy occurs at $12-24$ hour and fortnightly periodicities. The shallower the water, the greater its impact on vertical and horizontal mixing. Tidal currents exert a stress on the ocean bottom which mixes water in the manner analogous to wind-generated currents. Co-oscillating tides driven by oceanic forcing at the shelf edge produce changes in sea surface elevation, and strong tidal currents. If the tidal current amplitude is sufficiently large, and water depth shallow enough, then the tidally induced turbulence at the sea bed can penetrate through to the sea surface. The interaction of strong tidal currents with the bottom in shallow water (Stokes drift) is a particularly important process for horizontal advection. In regions where this turbulent bottom boundary layer reaches to the sea surface, the water column will usually be well mixed.

Stratified water may intersect the bottom in deep water where mixing is weak. If tidal forcing is strong enough, internal tides can be generated that can propagate both onshore and out into the deep ocean and provide mixing energy for the water column. This process occurs in upwelling zones along eastern boundary currents. The Gulf of Maine/Georges Bank and the Southeast Bering Sea are examples of regions of high tidal energy where vertical and internal tidal mixing are important.

Intense cooling of relatively warm shelf waters can remove large quantities of sensible and latent heat from shelf waters and thereby increase the density to the point that the water will sink. This convective process can lead to vertically homogeneous water in coastal regions. This occurs frequently in the South Atlantic Bight and in the Gulf of Mexico when cold continental air masses formed in winter move eastward over relatively warm shelf waters. Evaporation also increases the density of surface water by leaving salt behind, and may lead to convection. This process is important along the Texas Gulf Coast where hypersaline water, produced in the lagoons and estuaries, may be exported to the shelf.

\section{Buoyancy Forcing}

Input of heat through solar radiation and freshwater discharges are major sources of buoyancy which act to stratify the water column. The turbulent processes whereby the wind's momentum can erode the pycnocline and subsequently cause it to deepen are very complex and are usually parameterized in terms of some form of entrainment velocity or Richardson number, the latter measuring the combined influences of stratification and vertical shear. If buoyancy fluxes are greater than available sources of vertical mixing energy (the work due to surface and bottom stress), the water column is vertically stratified. The water column becomes vertically homogeneous when mixing energy overcomes the available buoyancy forces. Water depth is an important parameter which determines whether the water column will or will not be stratified under given levels of vertical mixing energy and buoyancy flux.

The input of heat through solar radiation lowers the density of surface water. A distinct upper layer is formed in the absence of vertical mixing, with a thermocline (pycnocline) at the base. As long as mixing forces are small, relative to the buoyancy forces, the water will remain stratified although the thermocline may strengthen and weaken and its depth change in response to time variations in mixing energy. This is a seasonally important process in just about any temperate coastal region.

Input of freshwater from land can spread out across the surface of more saline (and dense) sea water, and a two-layer system is often present in the absence of vertical mixing. The inner portions of continental shelves become vertically stratified when a high input of freshwater provides a strong flux of buoyancy relative to the tidal energy available for mixing. Increased 
tidal mixing relative to a constant buoyancy flux eventually produces vertically homogeneous estuaries.

Freshwater discharges from rivers supply variable buoyancy strengths to coastal environments (while precipitation on the sea surface is a source of buoyancy, its effect in coastal regions is usually small compared to that of river runoff). This variability consists of temporal variations in discharge of a single river, or variations in discharge from many rivers of many sizes. The Mississippi River is the largest of all U.S. rivers and extends a band of low salinity water around the Gulf of Mexico to Texas. The extent, both vertically and horizontally, however, is variable and is modulated by the Mississippi's discharge rate and processes which tend to disperse the plume, mainly wind stress.

Variations on this theme occur in the Gulf of Alaska and in the South Atlantic Bight. The former has large and multiple sources of freshwater discharge from glacier-fed rivers along a zone from British Columbia to the Aleutian Islands. Individual plumes blend to a low salinity band extending along the coastline overriding denser water of the Gulf of Alaska. A strong baroclinic coastal current is formed in this region. In contrast, the South Atlantic Bight has several medium-sized rivers that discharge to a relatively shallow continental shelf. Vigorous spring tides can vertically mix the low-salinity band to the bottom, while neap tides cannot quite do the job and the water near the coast is stratified. The structure of the resulting frontal zone is easily changed by fluctuating alongshore wind stress.

\section{Transport Processes}

Wind stress, especially the along-shore component, generates an across-shelf secondary circulation in coastal ecosystems. Depending on wind direction, the secondary circulation can either spread buoyant water offshore or confine it to the coast. If the depth of wind stress influence is of the order of $10 \%$ or less of the total water depth, the volume flux due to wind is at right angles to the surface stress. These conditions produce classical upwelling and downwelling circulation along coastal margins with associated adjustments in sea level, water mass and shore-parallel currents. The crossshelf fluxes are carried in surface and bottom frictional boundary layers. Downwelling is characterized by onshore/offshore flow in a surface/bottom boundary layer. Upwelling reverses the sense of this circulation.

The familiar cycles of upwelling and downwelling have been extensively studied and are relatively well understood along eastern boundary current regimes where the frictional boundary layers are separated by a geostrophic interior flow. However, in shallow portions of coastal regions - e.g., on the broad, shallow Northeast U.S shelves - the surface and bottom boundary layers are not necessarily separate. The resulting currents in such a regime influence the flux of material in a complex and little-understood way which depends importantly on the veering of horizontal currents from surface to bottom.

\section{Coastal Frontal Zones and Instabilities}

Frontal zones are regions which display combinations of temporal and spatial changes in buoyancy supply, vertical mixing and horizontal transport. Examples include boundary current fronts such as the Gulf Stream, upwelling fronts along eastern boundary currents, and shallow water coastal fronts. They occur where mixing processes which act to diffuse the front are overcome by buoyancy transport processes. There are three dynamic processes acting at most fronts found within coastal systems: (1) buoyancy supply along one side of the front; (2) along-front wind stress inducing cross-front advection of opposite sign in surface and bottom layers; and (3) vertical mixing of the front through such agents as surface wind work, tidal current work at the bottom, and convective overturning due to horizontal advection and atmospheric cooling.

While frontal zones, by nature, inhibit the cross-front transport of material, upwelling-favorable winds induce an offshore transfer of frontal zone water in the upper layers that is mixed with water seaward of the frontal zone, producing high vertical density gradients and low horizontal ones. Downwelling favorable winds produce the opposite and act to "pin" the frontal zone to the coast as a zone of high horizontal but low vertical density gradient. Abrupt changes from an upwellinginduced to a downwelling-induced frontal structure can occur on time scales of a few hours.

When buoyancy input (freshwater discharge) is sufficiently large compared to horizontal eddy diffusion, wave-like disturbances which grow in time (baroclinic instability) are triggered along the front. Baroclinic instability in coastal currents produce flow patterns which physically transport passive particles from one side of the front to the other and provides a mechanism that mixes coastal water with ambient ocean water. Transport mechanisms of this sort are found in many of the frontal zones present along coastal margins. Off the U.S. west coast, swirls, jets and eddies are produced by the interaction of the meandering California Current with coastal waters. Eddy structures playing a similar role are found on the western side of the Gulf Stream, along the shelf-break front in the Mid Atlantic Bight, and in the coastal Gulf of Alaska.

Mid-shelf fronts can be created when downwelling favorable wind stress at the shelf break drives oceanic water present at the shelf break landward over the continental shelf. A front is formed when this water converges with shelf water. For example, a strong crossfront density gradient is formed at mid-shelf when warm Gulf Stream water, triggered by a burst of alongshelf wind stress (downwelling favorable), converges with the colder and denser shelf waters. There is enhanced vertical mixing at the front as the warm salty water is cooled by air-sea interaction. When the wind relaxes, the water masses are unstable and the relatively dense water along the front slides underneath the 
outer shelf waters and cascades to deeper waters beyond the shelf break.

\section{Topographic Controls}

There are several obvious topographic controls on the circulation in coastal ecosystems. The shelf edge forms a natural boundary between physical processes in the open ocean and those on the shelf. It can be a region of significant upwelling, associated frontal formation, and biological activity. It can also support certain wave forms, namely shelf waves, which are intrinsically related to the slope of topography. Coastal features such as headlands also induce horizontal gyre-type circulations within which material can be trapped. Wind-induced setup and setdown of sea level against coastlines and associated pressure gradients can induce strong bottom currents, which when combined with wind waves, can move large volumes of material.

Currents at subtidal frequencies tend to follow isobaths, and current components directed across isobaths are usually relatively weak. However changes of topography associated with capes, ridges and troughs alter the flow along isobaths, and under such conditions the crossshelf flux of material becomes enhanced and density and momentum are redistributed. Capes induce upwelling through the conservation of vorticity which can enhance local biological productivity. Cape-induced upwelling is ubiquitous along east and west coasts.

Topographic features such as canyons and troughs that cut across the continental margin may intercept material transported along margins and convey the material up and down the canyon's axis. If the canyon is narrow, the cross-shelf sea level slope drives an ageostrophic current along the axis. Canyons may thus play a significant role in net long-term fluxes of material across margins.

\section{Numerical Models of the Coastal Ocean}

To properly represent the coastal ocean, numerical models applied to coastal environments must adequately handle the processes mentioned above that mix or stratify the water column. Since numerical circulation models "work" by integrating certain equations of motion over discrete intervals in space and time (the "grid spacing" and "time step," respectively), some physical processes will be explicitly resolved by the space/time grid and others will not. In the former case, the equations of motion should be capable of representing the phenomena of interest. In the latter, "subgridscale parameterizations" must be supplied to approximately incorporate the effects of unresolved processes.

With few exceptions, coastal circulation models are based on the so-called hydrostatic primitive equations. These are identical to the complete equations of fluid motion with only a few plausible assumptions. For the subgridscale, several approaches to parameterization are employed, including those based upon Richardson number and higher-order turbulence closure models. The problem becomes quite complex when the bottom contains movable material that, when suspended, further alters the balance between vertical mixing and buoyancy forces. See, for example, Haidvogel and Beckmann (1999) for an extended discussion of many of these issues.

Models of the coastal ocean circulation take on a variety of current forms. Although differences among them are numerous, the most important distinctions involve the treatment of topography, the space/time discretization of the continuum equations, and the subgridscale closures used to represent motions unresolved on the finite space/time grid. Examples of models featuring alternative treatments of topography and the vertical coordinate include those based upon isopycnal layers, geopotential levels, and topography-following ("sigma") surfaces. The last of these - in which
st coordinate line follows the bottom exactly - has traditionally been preferred for coastal modeling. Nonetheless, models based on non-terrainfollowing coordinates are also in use within U.S. coastal waters.

An important related issue arises in applications wherein the region being modeled is not self-contained (i.e. not bounded on all sides by solid walls), in which case so-called "open boundary conditions" need to be prescribed on the non-solid sidewalls. In principle, such open boundary conditions should appropriately represent the (two-way) exchange of information between the region being modeled and that which has been excluded. Unfortunately, no simple single approach to open boundaries is possible, necessitating much trail-and-error and problem-specific solutions.

Despite some exceptions, the real-time modeling systems in existence today (see below) have been typically based on one of three physical model paradigms. We mention the attributes of these three dynamical models next.

\section{The Princeton Ocean Model (POM)}

The Princeton Ocean Model (POM) is the most widely used of the baroclinic coastal ocean models. Based on a formulation by Alan Blumberg and George Mellor (Blumberg and Mellor, 1987), POM uses a sigma coordinate in the vertical and a structured finite difference grid in the horizontal. The equations of motion are the hydrostatic primitive equations described above, along with a non-linear equation of state for sea water, used to determine the in situ density. The parameterization of vertical mixing in POM follows the turbulence closure sub-model of Mellor and Yamada (1982) which includes prognostic equations for the turbulent kinetic energy and turbulence length scale. Horizontal mixing is parameterized using a Laplacian formulation with 
mixing coefficients proportional to the local grid spacing and velocity shears. The advective terms are treated with standard second-order-accurate differencing schemes in both time and space.

Boundary conditions at the surface include specification of fluxes of momentum, heat and salt. At the ocean bottom, a quadratic drag formulation is used for momentum; the normal fluxes of heat and salt are typically set to zero. At closed lateral boundaries, the normal fluxes of heat, salt and momentum are also assumed to vanish. The no-slip condition is applied on the tangential flow. While the model does not explicitly provide open boundary conditions, a table is provided in the User's Guide that describes a variety of choices for open boundary conditions and guidelines for their implementation in the code.

The model equations are discretized on the Arakawa C-grid, a commonly used staggered grid. Second-order accurate spatial differencing is used throughout. The temporal differencing uses a split- explicit numerical scheme in which the terms responsible for the fast surface gravity waves (otherwise known as the external or free surface mode) are treated using a much smaller time step than that for the internal mode. Leap-frog time differencing is used throughout with the exception of the horizontal diffusion terms which are lagged in time and the vertical diffusion terms which are treated implicitly.

The model is readily available and may be downloaded from the ftp site "ftp.gfdl.gov". The model website at www.aos.princeton.edu/WWWPUBLIC/ htdocs.pom/ is well maintained and offers, among other items, a list of publications that have used the POM formulation, a list of upcoming meetings pertinent to POM users, a "Frequently Asked Questions" list, and contributions from users on a variety of issues related to POM.

\section{The Regional Ocean Modeling System (ROMS)}

This terrain-following model hierarchy originated with the semi-spectral primitive equation model (SPEM; Haidvogel et al., 1991), which solved the hydrostatic, primitive equations subject to a rigid lid condition at the sea surface. An algorithmically compatible free sea surface model (SCRUM, the S-Coordinate Rutgers University Model) was originated by Song and Haidvogel (1994). A valuable feature, first introduced in SCRUM and then retrofitted into SPEM, is a generalized nonlinear terrain-following coordinate which can be configured to provide enhanced resolution at either the sea surface or sea floor. The newest free surface model in this hierarchy, the Regional Ocean Modeling System (ROMS), is an expanded version of SCRUM with a variety of new features including alternatives for highorder upstream-biased advection, for subgridscale parameterization, and for high-performance computing on SMP-class computer architectures.
The ROMS circulation model is numerically similar to POM in several important respects, for example, the use of a structured finite-difference C-grid in space, second-order numerical approximations, and splitexplicit time-stepping of the external gravity mode. There are several important algorithmic differences between POM and ROMS, however. These include the availability in ROMS of quasi-monotone advection schemes and higher-order, constancy preserving timestepping (Shchepetkin and McWilliams, 1998).

Several horizontal mixing operators in curvilinear coordinates are implemented in ROMS, including harmonic (Laplacian) and biharmonic forms for viscosity and diffusivity. The associated mixing coefficients for momentum and tracers can either be constants, gridsize-dependent, or time-varying (proportional to the properties of the flow field). Both harmonic and biharmonic mixing tensors can be rotated along other orientations (geopotential or isopycnal/epineutral). Turbulence closure is achieved using the KPP scheme (Large et al., 1994) modified to include overlapping surface and bottom boundary layers and wave-current interactions (Styles and Glenn, 1999).

ROMS has been designed to optimize it for the SGI PowerChallenge and the CRAY Origin 2000 architectures, with the potential of porting it to the CRAY T3E. This redesign includes the introduction of explicit twodimensional partitioning (blocking) into subdomains (tiles), which can be assigned to different processors. The sustained single-processor performance of this code is approximately 125 MFlops on the CRAY Origin 2000, with an estimated performance of 3.2 Gflops on 32 processors.

Finally, integrated packages for grid generation, Lagrangian particle trajectories, and post-processing and plotting of results are available. Further information, and code access, can be obtained via the web at http:// marine.rutgers.edu.

\section{The Dartmouth Finite Element Model (QUODDY)}

QUODDY is the current apex of a family of shelf circulation models developed at Dartmouth College over the past 15 years (Lynch and Werner, 1987, 1991). A distinguishing feature of these models is the use of unstructured grids of triangles for the horizontal discretization. This permits the use of freely variable resolution to fit topography and/or circulation features, thereby allowing for locally enhanced resolution in regions of particular interest. A general terrain-following coordinate system is used which supports userconfigurable, variable vertical resolution. The vertical coordinate options are thus a superset of conventional sigma systems.

Conventional boundary conditions are required at lateral boundaries, providing for tidal and subtidal forcing. A radiation boundary condition is a provisional 


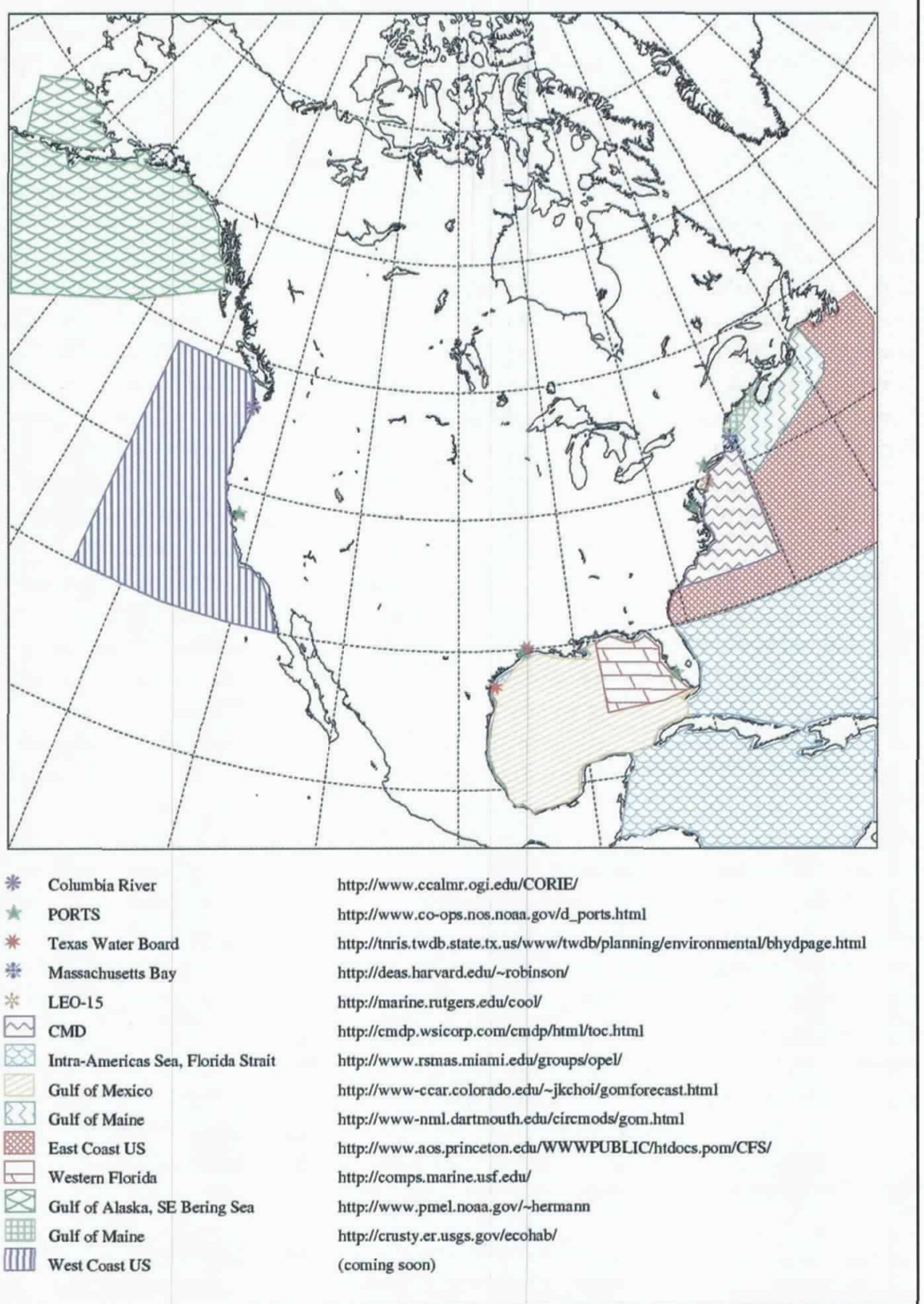

Figure 1: Geographical locations and web sites for some U.S. real-time coastal modeling systems

equations are rearranged to "wave equation" form which provides a parasite-free gravity wave propagation equivalent in accuracy to Arakawa $\mathrm{C}$ in finite difference technology. This form supports both explicit and semiimplicit time-stepping. The momentum equation is solved with implicit gravity, Coriolis, bottom stress, and vertical viscosity terms. Heat, salt, and turbulence transport are discretized similarly, with implicit vertical diffusion.

QUODDY is compatible with several accompanying models which generally have reduced physical features and operate on the same data structures. Included are two linearized 3-D models, a linear diagnostic model for periodic motions only, a $(\mathrm{z}, \mathrm{t})$ model describing momentum and turbulence variables in a horizontally homogeneous sea, and other related software.

The QUODDY Users' Group has been operative for about 3 years. It is an outgrowth of the Gulf of Maine modeling activity which spawned the software and the network of users. The URL for this location (QUG'99: wwwnml.dartmouth.edu/quoddy) is the gateway to all the software mentioned herein, along with its applications.

\section{Regional Applications}

A variety of "real-time systems" - which we define (somewhat vaguely) as those numerical-model-based systems

complement to the standard software. Lateral inputs of water, momentum, heat and turbulence are provided for river inputs. At the free surface, the model is forced by wind stress, heat flux and net volume flux. The bottom boundary condition is a quadratic stress law. A Mellor-Yamada level 2.5 turbulence closure is provided in the vertical scheme. As in POM, horizontal turbulence is closed in a Laplacian form which is shear- and mesh-size dependent.

The discretization is achieved with the Galerkin method on linear finite elements. The governing being routinely employed to deliver data-based hindcasts and/or forecasts of the physical circulation - are currently in operation in U.S. coastal waters. A summary of the geographical coverage of these systems is shown in Figure 1. Interestingly, the systems in operation today provide a cumulative coverage that encompasses very nearly the entire U.S. continental shelf (excluding the Arctic Ocean), and some significant pieces of the adjacent Atlantic and Pacific Ocean basins as well. Note that each of these systems provides varying degrees of spatial resolution. Normally, the larger the 
$98^{\circ} \mathrm{W} 96^{\circ} \mathrm{W} 94^{\circ} \mathrm{W} 92^{\circ} \mathrm{W} 90^{\circ} \mathrm{W} 88^{\circ} \mathrm{W} 86^{\circ} \mathrm{W} 84^{\circ} \mathrm{W} 82^{\circ} \mathrm{W}$

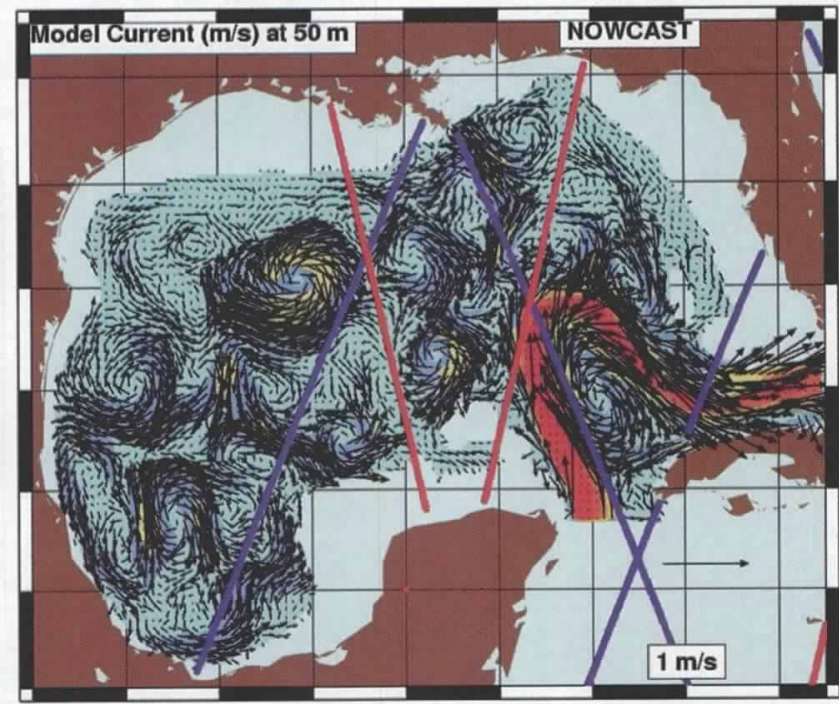

$98^{\circ} \mathrm{W} 96^{\circ} \mathrm{W} 94^{\circ} \mathrm{W} \quad 92^{\circ} \mathrm{W} \quad 90^{\circ} \mathrm{W} 88^{\circ} \mathrm{W} \quad 86^{\circ} \mathrm{W} 84^{\circ} \mathrm{W} 82^{\circ} \mathrm{W}$

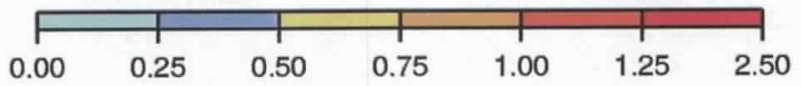

$98^{\circ} \mathrm{W} 96^{\circ} \mathrm{W} \quad 94^{\circ} \mathrm{W} \quad 92^{\circ} \mathrm{W} \quad 90^{\circ} \mathrm{W} \quad 88^{\circ} \mathrm{W} \quad 86^{\circ} \mathrm{W} \quad 84^{\circ} \mathrm{W} \quad 82^{\circ} \mathrm{W}$

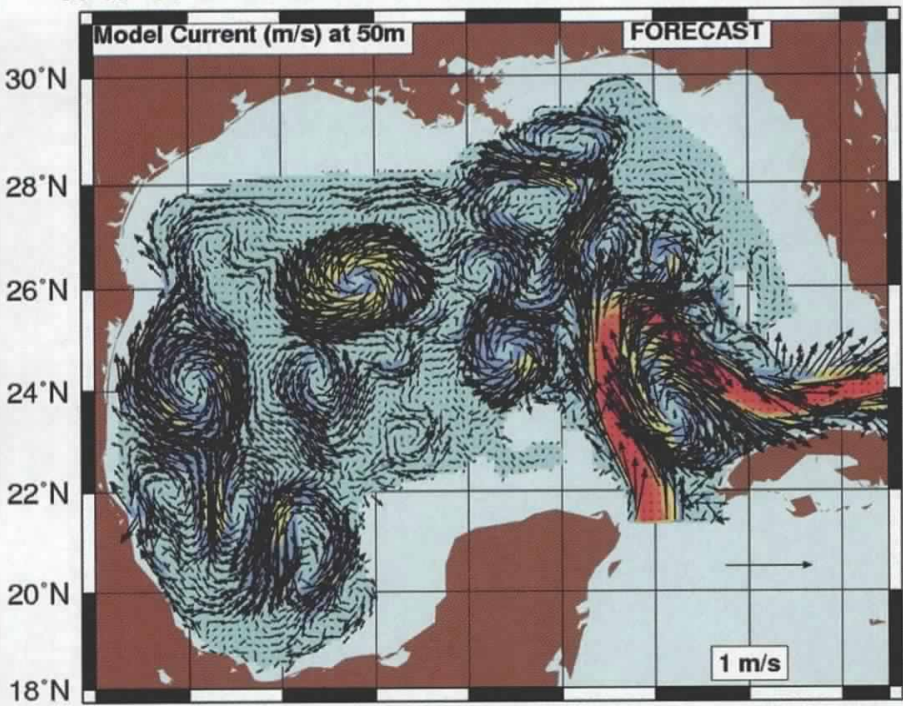

$98^{\circ} \mathrm{W} \quad 96^{\circ} \mathrm{W} \quad 94^{\circ} \mathrm{W} \quad 92^{\circ} \mathrm{W} \quad 90^{\circ} \mathrm{W} \quad 88^{\circ} \mathrm{W} \quad 86^{\circ} \mathrm{W} \quad 84^{\circ} \mathrm{W} \quad 82^{\circ} \mathrm{W}$

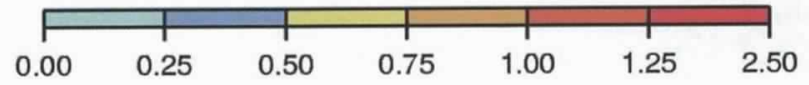

Figure 2. Snapshots of currents $(\mathrm{m} / \mathrm{s})$ at $50 \mathrm{~m}$ depth from the nowcast (left) and 2 week forecast (right) on January 8, 1999.

region covered, the less fine the grid spacing. For example, the LEO-15 system (Figure 1) covers a $30 \mathrm{~km}$ by $30 \mathrm{~km}$ block of ocean at a minimum spacing of 300 meters, whereas resolution within the coastal Gulf of Alaska is closer to $20 \mathrm{~km}$.

It is beyond our intent to review all these real-time systems in detail. Fortunately, many of the systems noted in Figure 1 have well-developed web sites from which specific information may be obtained. We refer the interested reader to the web sites noted in the figure. What follows is a brief "tour" of the U.S. continental waters, giving at least a flavor of some of the current systems and their capabilities.

\section{The Gulf of Mexico}

The Gulf of Mexico (GOM) modeling effort-funded by the Climatology and Simulation of Eddies (CASE) oil industry consortium-uses the POM model together with the assimilation of satellite altimeter data. The primary motivation for the development of the Gulf of Mexico real-time modeling system is the nowcasting and forecasting of strong currents-both at depth and at the surface - that could impact oil exploration and drilling operations, which cease in deep water when current magnitudes exceed 2 knots. Hence, of principal interest is the variability of the Loop Current, including the characteristics of the Loop Current front, the intrusion of the Loop Current into the Gulf of Mexico, the shedding of large anticyclonic eddies from the Loop Current, and the subsequent "westward" propagation of the eddies to the western portions of the basin.
The University of Colorado version of POM (CUPOM) forms the basis of the GOM modeling system. The basic GOM model has $1 / 5^{\circ}$ grid resolution, 21 vertical levels and the inclusion of fresh water input from major rivers around the basin. Altimeter data from TOPEX-POSEIDON and ERS-2 are assimilated into the model via an optimal-interpolation-based method that converts along-track sea surface height anomalies into pseudo-temperature anomalies throughout the water column and subsequently nudges them into the model solution. The model sea surface temperature is relaxed to 5-day composite values while surface salinity is relaxed to seasonal values. Six-hourly winds from the FNMOC/NOGAPS operational atmospheric model together with the specification of monthly varying Yucatan Channel inflow are used to drive the model.

Presently, the near real-time forecasts using the GOM model demonstrate skill up to 1-2 weeks (Figure 2). Future upgrades to the model, such as increasing the grid resolution to $1 / 12$ and improving the specification of the inflow boundary condition, are expected to extend the period of forecast skill to 3-4 weeks. It should be noted that due to the proprietary nature of these near real-time forecasts, the model results are available to the public only after a six-week delay. Additional information about the system may be viewed at the project website www-ccar.colorado.edu/ jkchoi/gomforecast.html.

\section{The New York Bight}

The Rutgers University Long-term Ecosystem Observatory (LEO-15; Glenn et al., 1998) is an instru- 
mented natural littoral laboratory that spans the $3 \mathrm{~m}$ to $30 \mathrm{~m}$ water depths offshore of Tuckerton, NJ with a 30 $\mathrm{km} \times 30 \mathrm{~km}$ well-sampled research space. Real-time surface data from remote sensing platforms, combined with real-time subsurface data from remotely operated and autonomous nodes, provide 3-D nowcasts to guide adaptive sampling with up to five coastal research vessels and a fleet of AUVs (Glenn et al., this volume). The real-time forecast system at LEO-15 utilizes a version of the ROMS model on a high-resolution (subkilometer) grid covering the New York Bight. Highresolution atmospheric forcing is obtained from concurrent forecasts of atmospheric conditions using a mesoscale meteorological model.

A series of Coastal Predictive Skill Experiments (CPSE) were begun at LEO-15 starting in 1998. The summer 1998 CPSE focussed on improving nowcast skill for adaptive sampling using spatially extensive real-time data. The phenomenological focus of the CPSE is the development of recurrent coastal upwelling centers and their effect on phytoplankton and suspended sediment distributions. Figure 3 illustrates the initial development of an upwelling center in which the ocean model has assimilated radial currents from each of two on-shore CODAR HF-Radars. The initial development is characterized by the cyclonic curvature in the northward flowing upwelling jet and the surfacing of the cold upwelled water nearshore.

Three days later, the upwelling jet was now meandering around a cyclonic eddy embedded within the cold upwelling center. Data-based nowcasts and model forecasts were used to define three cross-shelf transects for sampling over a two-day period (Figure 3). The alongshore current component thus acquired by the REMUS survey vehicles indicated that the northwardflowing upwelling jet on the offshore side was confined to the region above the thermocline, and revealed in addition a southward-flowing, subsurface jet on the nearshore side. The systems towed along the northern transect uncovered a similar velocity structure, with the highest phytoplankton concentrations of the season discovered within the subsurface jet. The subsurface adaptive sampling data suggest that phytoplankton concentration increases within the upwelling center may be dominated by advection from the north. Up-todate results from the LEO effort can be found at http://marine.rutgers.edu.

\section{The Gulf of Maine}

The Gulf of Maine represents a major international resource, with heightened interest in recent decades in tidal power, oil and gas, and fisheries. Generally, all important shelf processes are operative in the Gulf, including two primary and distinct inflows across the Scotian Shelf and through the Northeast Channel; deepwater formation in the three major Gulf basins; tides, tidal mixing, and tidal rectification; wind; stratification
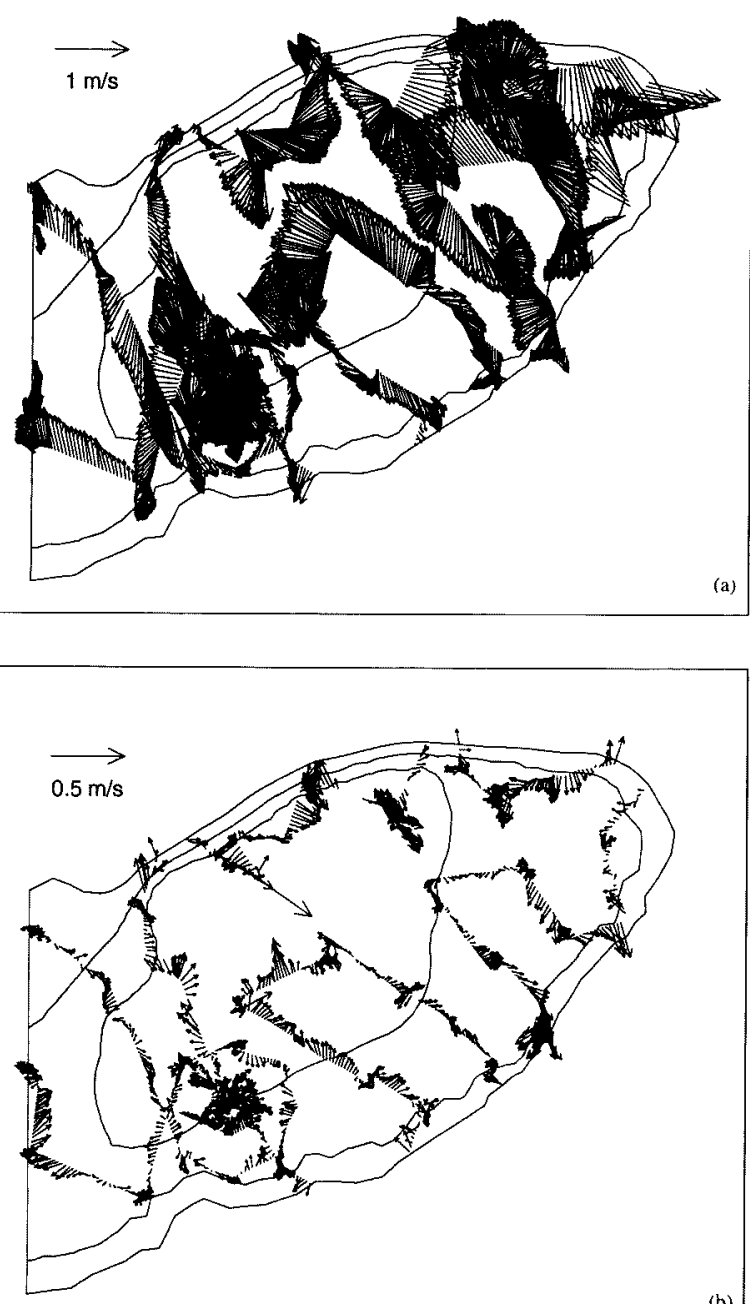

(b)

Figure 3: (a) Observed ADCP from cruise EN265. The dominant signal is the tidal current. The sampling requires approximately 10 days. From Lynch et al., 1998. (b) Unexplained current from EN265, following inversion. Note the change in scale.

and frontal circulation; freshwater inflow along the coast; and local estuarine processes. The resolution demands can be overwhelming in this region. Tidal rectification and frontal circulation can demand resolution of order $2 \mathrm{~km}$, while properly equilibrated inflows from the Scotian Shelf demand upstream spatial coverage of order 4 shelf widths, i.e., horizontal coverage of order $1000 \mathrm{~km}$.

The Gulf has served as a development laboratory for the Dartmouth Shelf Models for a decade. The primary interest has been from two contemporary research programs: the U.S. GLOBEC program which focused on Georges Bank; and the Regional Marine Research Program, which focused on the Maine Coastal Current. The basic model domain extends from the Laurentian Channel to the western tip of Long Island, and seaward to roughly the $1000 \mathrm{~m}$ isobath, beyond which it terminates in a gently sloping idealized ocean. Baseline 
TEMPERATURE AND 10m CURRENTS

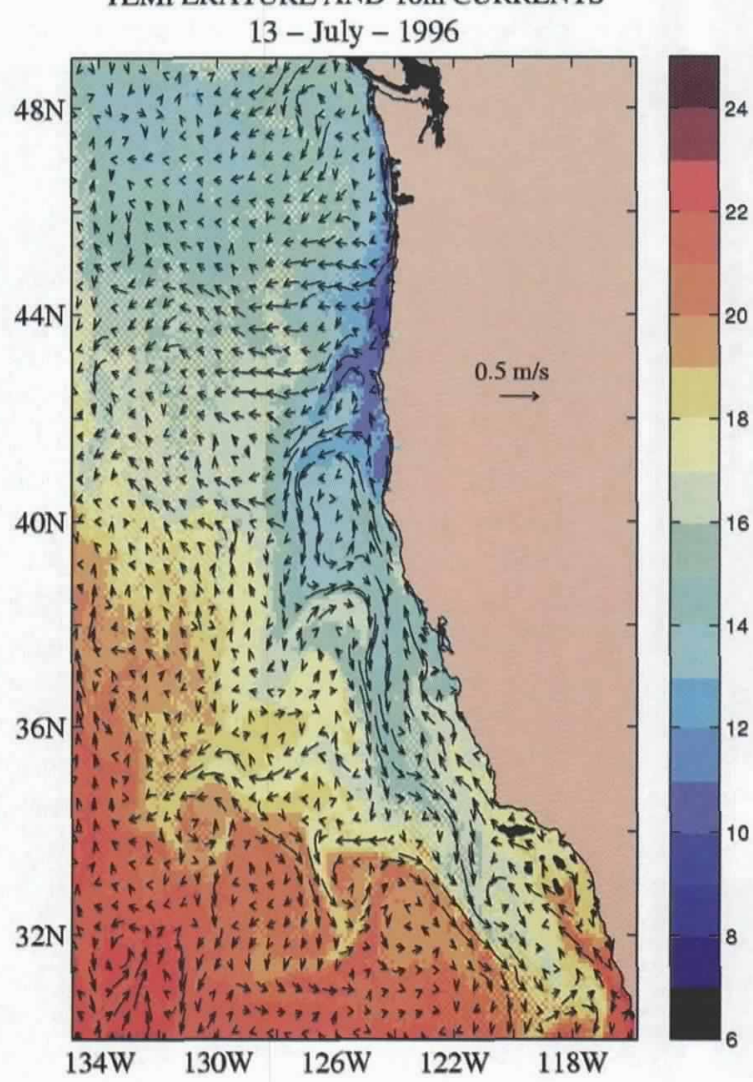

SALINITY AND $10 \mathrm{~m}$ CURRENTS

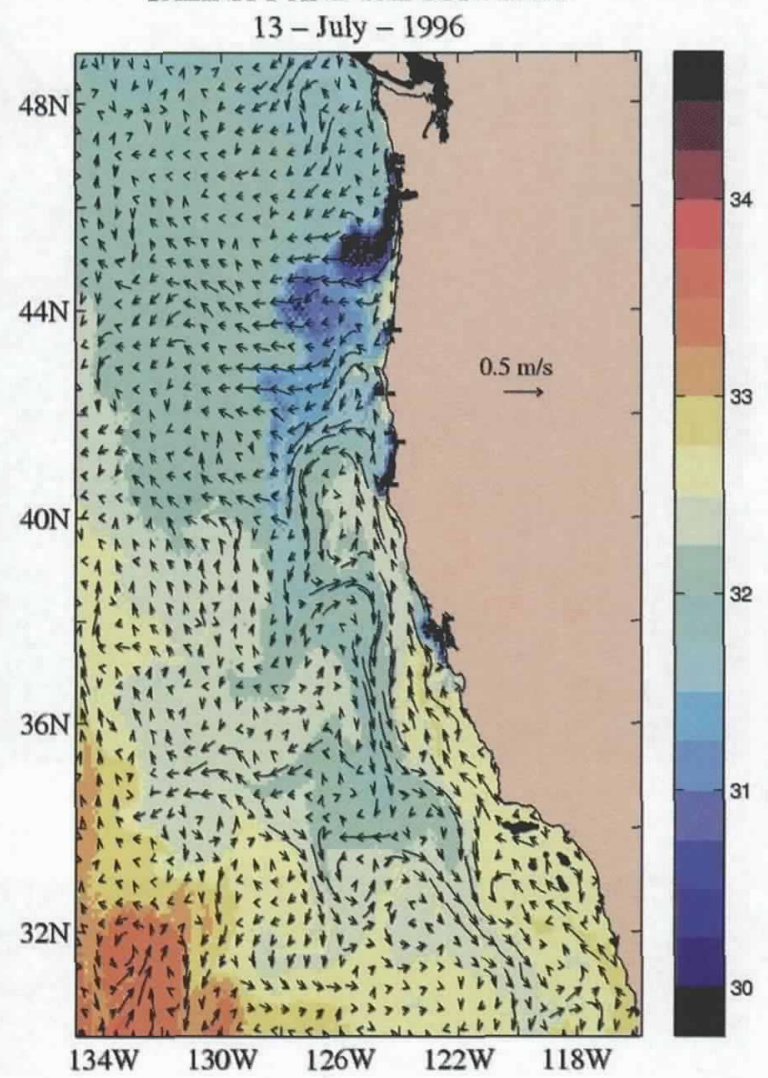

Figure 4: Snapshots from the PWC simulation of contours of (left) surface temperature $\left({ }^{\circ} \mathrm{C}\right.$ ) and (right) surface salinity (psu) superimposed with 10m-level current vectors for 13 July 1996. The offshore displacement of the coastal jet and the subsequent appearance of the poleward coastal current are clearly depicted.

resolution on Georges Bank, for example, is of order 3 $\mathrm{km}$, and approaches $2 \mathrm{~km}$ across the steep northern flank.

A series of hindcasting exercises was initiated with the objective to assimilate observed wind, CTD and $\mathrm{ADCP}$ data to deduce the actual circulation conditions on Georges Bank. Figure 3a shows the observed velocity during one GLOBEC cruise. Tides are dominant. The procedure was to make a QUODDY run forced with climatology as best prior estimate of the boundary conditions, and observed winds, and initialized with observed hydrography. The discrepancies were inverted, and the procedure repeated iteratively. The remaining unexplained velocity from this exercise is depicted in Figure 3b. These hindcasting experiments are described in Lynch et al. 1998).

In April-June of 1999, the first operational exercise was carried out at sea, with daily QUODDY forecasts of the Georges Bank circulation. This real-time assimilation procedure using a climatological prior estimate of forcing and circulation; sequential forecasts of atmospheric forcing and related oceanic wind-band pressure boundary conditions; and assimilation of
CTD, drifters, and ADCP data. The experiment showed that using today's workstations, a 3-day limited-area forecast can be computed at sea within a half-day of the closing time for atmospheric data.

\section{The California Current System}

The real-time nowcast/forecast system for the west coast-a U.S. Navy funded project-utilizes the POM model. The Pacific West Coast (PWC) model was cooperatively developed by the Navy's Fleet Numerical Meteorology and Oceanography Center (FNMOC) and the Naval Research Laboratory (NRL) as a first generation real-time coastal ocean model that is embedded within a large-scale model (basin wide or global) to obtain its open boundary information (Clancy et al., 1996). The model, which continues to evolve, is currently run in near real-time as a component of NRL research projects.

The regional domain of the PWC model extends from $30^{\circ} \mathrm{N}$ to $49^{\circ} \mathrm{N}$ and from the coast to $135^{\circ} \mathrm{W}$. The grid resolution is $1 / 12^{\circ}$ with 30 levels in the vertical. The bottom topography is based on the Navy's DBDB5 (Digital Bathymetry Data Base $5^{\circ}$ ) with a mild amount of 

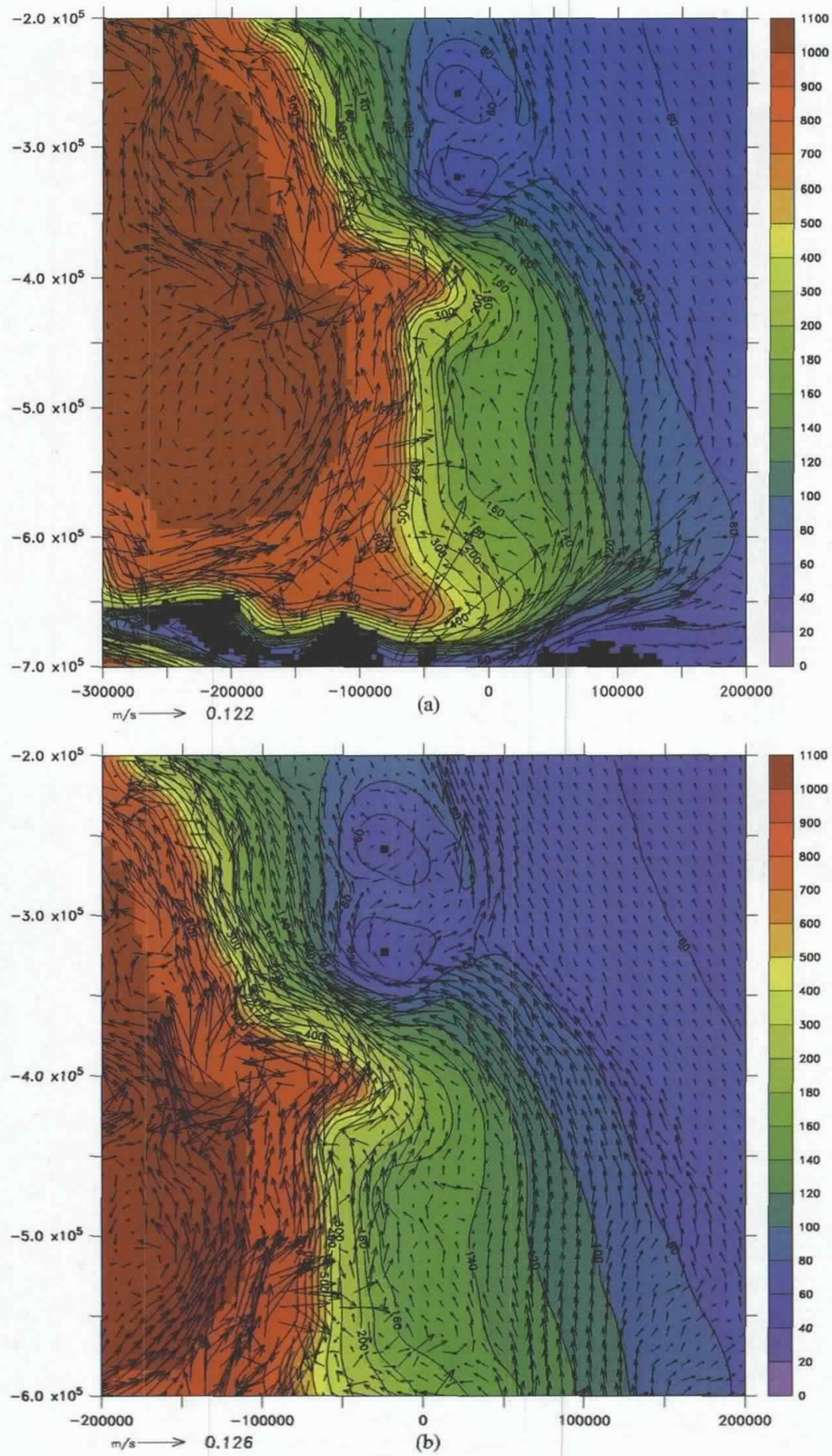

Figure 5: De-tided circulation at day 98 of a hindcast for year 1997 from the regional Bering Sea model: (a) Southeast Bering Sea and (b) Bering Slope region. Scales show depth in meters.

smoothing. The input from seven major rivers is included by specifying the monthly varying, depth averaged fresh water runoff values. Climatological values of temperature and salinity are obtained from the Navy's General Digital Environmental Model (GDEM) database. The surface momentum fluxes for the simulation are the 12-hourly hybrid FNMOC/NOGAPSHellerman and Rosenstein wind stress values in which the long-term mean of the Navy's NOGAPS stresses are replaced by the mean of the Hellerman and Rosenstein's monthly climatological values. Surface salinity is relaxed to monthly climatological values while sea surface temperature is relaxed to 5-day composite fields.

At lateral open boundaries, the coastal model receives boundary information from the global NRL Layered Ocean Model (NLOM). The NLOM model, which has a grid resolution of $1 / 4^{\circ}$ and 6 vertical layers, is driven by the same forcing as the coastal model. Additionally, it assimilates sea surface height data derived from the TOPEX-POSEIDON and ERS-2 satellite altimeters. The sea surface height anomalies and the vertically averaged velocities across the open boundary, as determined from the NLOM simulation, are used to drive the external mode of the PWC. The internal mode at the boundary is governed by a radiation open boundary condition; for flow into the PWC region, monthly varying climatological values of temperature and salinity are used.

Without data assimilation, the PWC model is not able to accurately reproduce many of the mesoscale features associated with the California Current System. However, the model is able to represent many characteristics of observed features such as filaments, coastal upwelling regions, the seasonal variation of the coastal jet, the appearance of the inshore poleward surface current (Davidson Current) and the poleward undercurrent (Figure 4). Future changes to the system include the utilization of a basin-scale sigma coordinate model to provide the boundary information for the high-resolution coastal simulation.

\section{The Alaska Continental Shelves}

Under support from the SouthEast Bering Sea Carrying Capacity (SEBSCC) project, and other related national programs (e.g., GLOBEC, FOCI), a team of investigators led by Dr. Al Hermann has been developing and applying a sequence of coupled hydrodynamic numerical models to simulate regional transport patterns in the Northeast Pacific and the Bering Sea, and to investigate physical linkages across this range of spatial scales. The overall approach is to embed a high-resolution regional model within an outer model covering the adjacent basin-scale ocean. Within the local Southeast Bering Sea (SEBS) region, the SCRUM model is being used. In the outer region, variable spatial resolution is a requirement; there, a high-order finite element model (SEOM; see Haidvogel 
and Beckmann, 1999) is applied. The utilization of unstructured grids in the large-scale model allows the incorporation of the entire globe, but at varying resolution appropriate to a regional focus on the Northeast Pacific and Bering Sea.

As an initial step in the development of the coupled coastal/basin-scale model hierarchy, and because of their local importance in the SEBS, multi-component tidal simulations have been considered first. Data obtained from these simulations compare favorable with local tidal observations in the SEBS, and with prior numerical realizations of tides in the SEBS. The SEOM output, subsampled on a regular regional grid in the SEBS, has been stored for use as tidal inputs to the local SEBS model.

The regional Bering Sea model, forced by these externally generated tidal data, has been shown to replicate spatial patterns of tidal amplitude (M2 and K1), tidal residual flows around the Pribilof Islands, subtidal flows along the shelf break and North Aleutian Slope, intense eddy activity in the deep basin, and basic cross-shelf hydrographic structure. Figures $5 \mathrm{a}$,b illustrate low-pass filtered (de-tided) results at day 98 of a hindcast for year 1997 with tidal (M2, K1, S2, N2, O1) and subtidal boundary forcing, ECMWF winds, and climatological heat flux. The deep basin has filled in with an energetic eddy field (Figure 5a). Irregular flows along the Bering Slope (Figure $5 b$ ) are suggestive of the chaotic mode of observed flow. A jet of moderate alongshelf flow is evident centered on the $100 \mathrm{~m}$ isobath, and cross-shelf exchange is evident near the shelf-break. Tidal residual flow is evident as a clockwise circulation around the Pribilof Islands, superimposed on the other subtidal circulation. Animations of the tidal and subtidal circulation near the Pribilof Islands, an illustration of $\mathrm{K} 1$ tidal amplitude, and other model features are available on the Web at www.pmel.noaa/gov/hermann/sebscc.html.

\section{Toward the Future}

As this review indicates, much expertise has been developed in recent years in regional numerical modeling of circulation in U.S. coastal waters. Though not explicitly reported here, this progress also extends to the modeling of coupled physical/ biological/opti$\mathrm{cal} /$ atmospheric interactions. Many of the principal coastal regions surrounding the U.S. are presently being explored in real-time or near-real-time using the combined assets of these real-time observational/modeling systems. (See also two articles by Glenn et al. and Walstad and McGillicuddy in this volume.) Notwithstanding this progress, however, several technical and scientific challenges remain. These include, but are not limited to, better subgridscale closures for use in shallow coastal waters, systematic inter-model testing and the development of quantitative measures of skill and performance, and enhanced procedures for data assimilation and state estimation. Progress in all of these areas will be necessary to meet the goals of an integrated observing/modeling system for the U.S. continental shelves.

\section{Acknowledgements}

The authors gratefully acknowledge funding for these activities from the following agencies: the National Science Foundation, the Office of Naval Research, The National Ocean Partnership Program, and the National Ocean and Atmospheric Administration. The final version of this manuscript was prepared by the first author while on leave at the University of California, Berkeley. Research in Science is also acknowledged.

\section{REFERENCES}

Blumberg, A.F. and G.L. Mellor, 1987: A Description of a three-dimensional coastal ocean circulation model. In: Three-dimensional coastal ocean models, N. Heaps (ed.) American Geophys. Union, New York, NY, 208 pp.

Brink, K.H. and A. R. Robinson, eds., 1998: The Sea, vol. 10, John Wiley and Sons, Inc., New York; 604 pp.

Clancy, R.M., P.W. deWitt, P. May and D.S. Ko, 1996: Implementation of a coastal ocean circulation model for the west coast of the United States. In: Proceedings of the American Meteorological Society Conference on Coastal Ocean and Atmospheric Prediction. pp 72-75. Atlanta: American Meteorological Society.

Glenn, S.M., D.B. Haidvogel, O.M.E. Schofield, J.F. Grassle, C.J. von Alt, E.R. Levine and D.C. Webb, 1998: Coastal Predictive Skill Experiments at the LEO-15 National Littoral Laboratory. Sea Technology, April, 63-69.

Haidvogel, D.B., J.L. Wilkin and R. Young, 1991: A semispectral primitive equation ocean circulation model using vertical sigma and orthogonal curvilinear horizontal coordinates. J. Comput. Phys., 94, 151-185.

Haidvogel, D.B. and A. Beckmann, 1998: Numerical modeling of the coastal ocean. The Sea, vol. 10, K. H. Brink and A. R. Robinson, eds.; 457-482.

Haidvogel, D.B. and A. Beckmann, 1999: Numerical Ocean Circulation Modeling. Imperial College Press, London; $320 \mathrm{pp}$.

Large, W.G., J.C. McWilliams and S.C. Doney, S.C., 1994 : Oceanic vertical mixing: a review and a model with a nonlocal boundary layer parameterization. Rev. Geophys., 32, 363-403.

Lynch, D.R., C.E. Naimie and C.G. Hannah, 1998: Hindcasting the Georges Bank circulation, Part I: Detiding. Cont. Shelf Res., 18, 607-639.

Lynch, D.R. and F.E.Werner, 1987: Three-Dimensional Hydrodynamics on Finite Elements, Part I: 
Linearized Harmonic Model. Int. J. Num. Meths. in Fluids, 7, 871-909.

Lynch, D.R. and F.E. Werner, 1991: Three-Dimensional Hydrodynamics on Finite Elements, Part II: Nonlinear Time-Stepping Model. Int. J. Numerical Methods in Fluids, 12, 507-533.

Mellor, G.L. and T. Yamada, 1982: Development of a turbulence closure model for geophysical fluid problems. Geophys. and Space Phys., 20, 851-875.

Shchepetkin, A.F. and J.C. McWilliams, 1998: Quasimonotonic advection schemes based on explicit locally adaptive dissipation. Monthly Weather Rev., 126, 1541-1580.

Song, Y. and D.B. Haidvogel, 1994: A semi-implicit ocean circulation model using a generalized topography following coordinate system. Journal of Computational Physics, 115, 228-244.

Styles, R. and S.M. Glenn, 1999: Modeling Stratified Wave-Current Bottom Boundary Layer Model for the Continental Shelf. J. Geophys. Res., submitted. DJ 